archives

of thermodynamics

Vol. 31(2010), No. 3, 131-144

DOI: $10.2478 /$ v10173-010-0019-4

\title{
The influence of external cooling system on the performance of supercritical steam turbine cycles
}

\section{WOJCIECH KOSMAN}

Silesian University of Technology, Institute of Power Engineering and Turbomachinery, Konarskiego 18, 44-100 Gliwice, Poland

\begin{abstract}
The problem presented in this paper refers to the concepts applied to the design of supercritical steam turbines. The issue under the investigation is the presence of a cooling system. Cooling systems aim to protect the main components of the turbines against overheating. However the cooling flows mix with the main flow and modify the expansion line in the steam path. This affects the expansion process in the turbine and changes the performance when compared to the uncooled turbine. The analysis described here investigates the range of the influence of the cooling system on the turbine cycle. This influence is measured mainly through the change of the power generation efficiency. The paper explains the approach towards the assessment of the cooling effects and presents results of the modeling for three supercritical steam cycles.
\end{abstract}

Keywords: Steam turbine; Supercritical steam; Cooling; Efficiency

\section{Nomenclature}

$\begin{array}{lll}c & - & \text { cooling (subsript) } \\ m & - & \text { cooling flow, } \mathrm{t} / \mathrm{h} \\ N_{e l} & - & \text { gross electric power, } \mathrm{MW} \\ T & - & \text { temperature, }{ }^{\circ} \mathrm{C} \\ \eta & - & \text { cycle efficiency, } \%\end{array}$

*E-mail address: wojciech.kosman@polsl.pl 


\section{Introduction}

In modern supercritical steam turbines the level of the live steam temperature $[1,2]$ reaches $600{ }^{\circ} \mathrm{C}$. The reheat steam enters the intermediate turbine part at even higher temperature level of $620^{\circ} \mathrm{C}$. Some more advanced projects $[3,4]$ assume the live and reheat steam at respectively 700 and $720^{\circ} \mathrm{C}$. Such high values result in thermal loads that require advanced materials for rotors and casings, which are able to resist high temperature and stresses [5].

The range of application of the advanced and expensive materials may be limited if a cooling system is applied. Cooling systems are common in gas turbines and now they become essential also in steam applications. The key idea behind any cooling system is the presence of an additional flow at lower temperature than the main flow in the sections of the turbine where the thermal loads reach the highest level. Cooling systems affect a turbine in two aspects, described below.

\subsection{Decreased thermal load}

Surfaces of components of a turbine are exposed to a flow at lower temperature than the main flow. This changes the conditions of the heat transfer in the components. In details the effects may vary: temperature of the components may be lower or a temperature field in the components may be more uniform, which results in lower thermal stresses. The exact effect depends on the geometry of the cooling passages and the component.

\subsection{Decreased cycle efficiency}

Although a specific design of a cooling passages may take various forms, a cooling flow always mixes with the main flow. The mixing process affects an expansion line in a turbine and decreases the performance of a steam cycle from a thermodynamical point of view. It is a side effect of a cooling process: the temperature of the cooled components is lower at the price of a worse performance.

The research described in this paper aims to investigate the effects of the external cooling on the whole steam turbine cycle. The primary value under the investigation is the power generation efficiency. It is calculated here for various cooling conditions and compared to an uncooled cycle. Cooling conditions are expressed by the amount of the cooling steam and its temperature. 
Thermal states of turbine components are also analyzed here in order to assess the influence of a cooling system in both aspects mentioned above. The analysis involves the investigation of a temperature field in a rotor.

\section{Cooling systems}

An example of a cooling system is shown in Fig. 1. This is the system in a reaction turbine, located near the inlet of the live steam, which is the area of the highest temperature level. Cooling steam flows near the surface of the rotor in the steam inlet area and is separated from the main flow. In other words the rotor surface is exposed only to the cooling flow and therefore is protected against the hot live steam.

Then the cooling steam flows through the passages at the roots of the blades. The mixing process occurs mainly in the first stage of the turbine but a part of the cooling flow reaches also the second stage. When the cooling flow leaves the passages, it creates a layer, which still separates the main flow from the rotor surface. The size of the layer depends on the amount of the coolant.

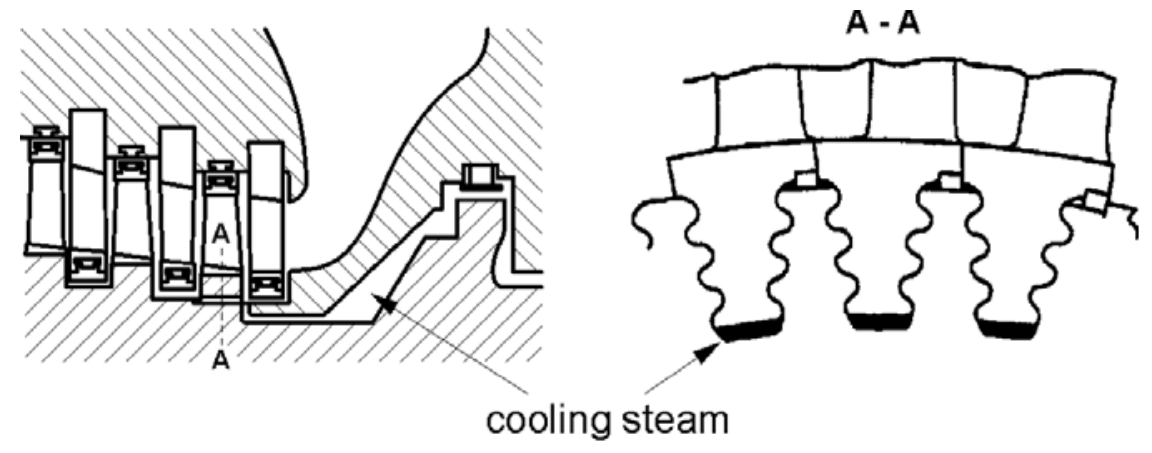

Figure 1. Design of cooling passages.

The cooling steam for a high pressure turbine part is usually taken from a location between the stages of a superheater. The steam that feeds the cooling system in the intermediate turbine part may be delivered from various locations. One of the possible solutions is presented in Fig. 2. The cooling steam is extracted from the outlet of the high pressure (HP) turbine. This means that the cooling steam parameters depend on the expansion process in the high pressure turbine part. 


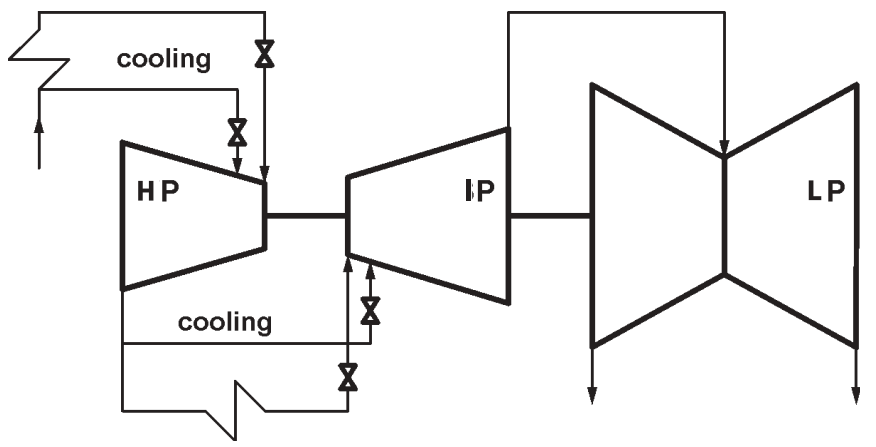

Figure 2. Delivery of the cooling flows to a turbine (design case 1).

Another design is shown in Fig. 3. The cooling steam is taken from the extraction of the high pressure part. In this case the temperature of the cooling steam is higher than in the case presented in Fig. 2. When

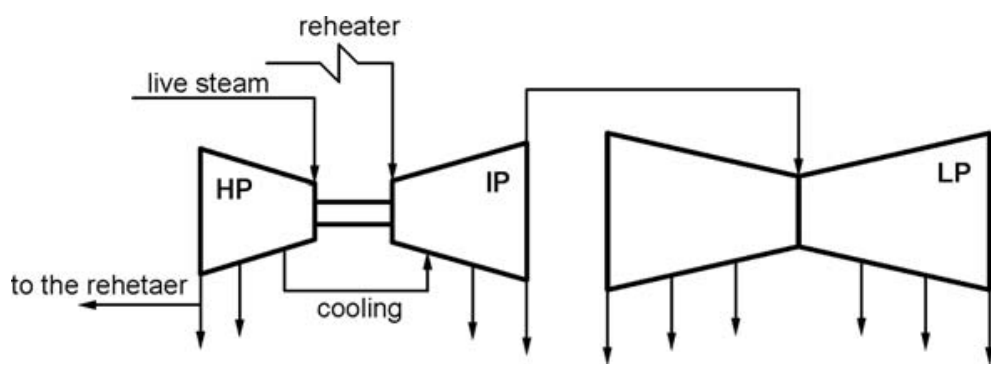

Figure 3. Delivery of the cooling flows to a turbine (design case 2).

analyzing together both solutions presented above (in Fig. 2 and 3) it is worth to notice that the range of the parameters of the steam taken into the cooling passages is quite wide. This information is important when forming the assumptions for the analysis.

\section{Analyzed cycle}

The arrangement of the cycle for the analysis is shown in Fig. 4. This is a typical cycle for supercritical steam turbines with high, intermediate and low pressure (LP) sections. The LP part usually has a double flow design but in the figure it is shown as a single flow section for simplicity. The 
cycle described here was used in the calculations with three distinct set of values of live and reheat steam parameters. This allowed to compare the effects of the cooling on various size steam turbines. The values of the steam parameters are gathered in Tab. 1.

In order to determine the cycle efficiency the calculations required a model that could simulate the operation of the whole power generation unit. Apart from the turbines, the model included the condenser, low and high pressure heat regeneration exchangers, deaerator and feedwater pumps driven by an auxiliary steam turbine.

The numerical results were obtained for the following assumptions:

- The pressure in the condenser is kept at the same level for all of the cases under the analysis.

- The amount of the cooling steam in the high pressure part varies between 0 and $8 \%$ of the flow through the steam boiler ( $m_{0}$ in Fig. 4$)$.

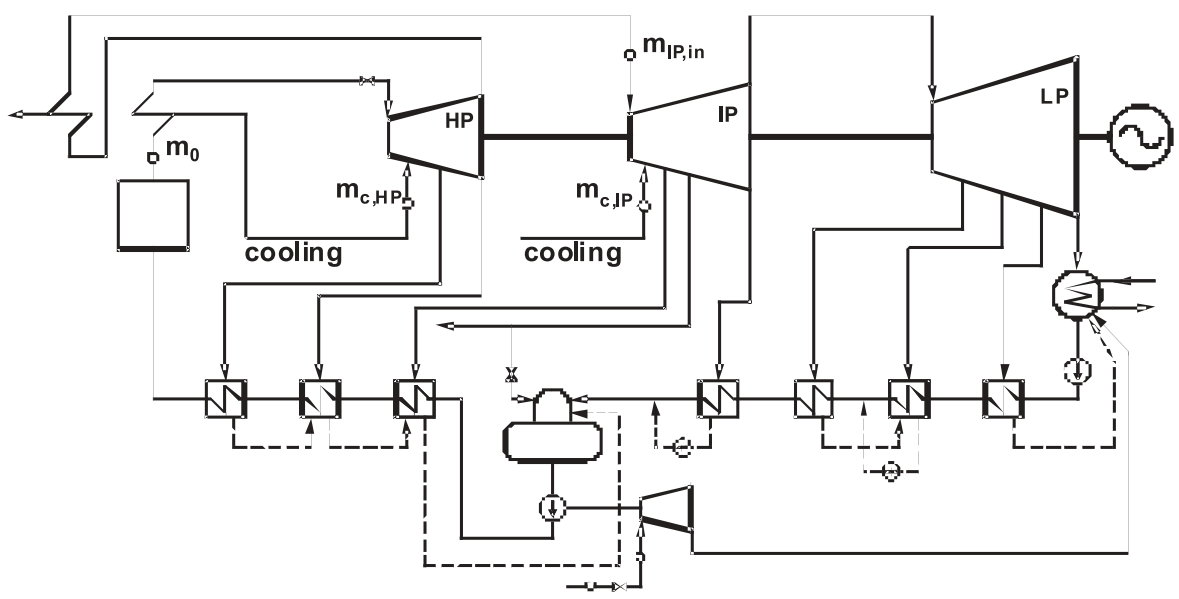

Figure 4. Supercritical steam turbine cycle.

- The amount of the cooling steam in the intermediate pressure (IP) part varies between 0 and $8 \%$ of the flow, which enters the intermediate part $\left(m_{I P, \text { in }}\right.$ in Fig. 4$)$.

- Since the cooling steam for the intermediate section may be delivered from various locations, the analysis included a wide range of temperature values of the IP coolant. Also this temperature was assumed independent of the expansion process in the HP turbine. 
Table 1. Live and reheat steam parameters

\begin{tabular}{|c|c|c|c|c|}
\hline \multirow{3}{*}{ Parameter } & \multirow{3}{*}{ Unit } & \multicolumn{3}{|c|}{ Cycle } \\
\hline & & case $\mathrm{A}$ & case B & case $\mathrm{C}$ \\
\hline & & supercritical & $\begin{array}{l}\text { intermediate } \\
\text { supercritical }\end{array}$ & $\begin{array}{c}\text { ultra- } \\
\text { supercritical }\end{array}$ \\
\hline live steam pressure & $\mathrm{MPa}$ & 28.5 & 27.5 & 35.0 \\
\hline live steam temperature & ${ }^{\circ} \mathrm{C}$ & 600 & 560 & 700 \\
\hline reheat steam temperature & ${ }^{\circ} \mathrm{C}$ & 620 & 580 & 720 \\
\hline
\end{tabular}

- Each set of the results obtained from the calculations represents design conditions. This means that each simulation corresponds to a different turbine with a specific amount of a cooling steam. It is reflected in the calculations by keeping the values of isentropic efficiencies, heat exchanger efficiencies and other performance indices of the auxiliary equipment constant between the simulations. Such an approach is justified under the assumption that the components of the cycle are carefully selected for each turbine and operate with the best possible performance, which is a common design approach.

- The modeling of the cooling system involves a simplified approach explained in details in the next section of this paper.

Table 2. Cooling steam parameters.

\begin{tabular}{|l|c|c|c|}
\hline \multirow{2}{*}{ Cycle } & \multicolumn{3}{|c|}{ Cooling flow temperature } \\
\cline { 2 - 4 } & case 1 & case 2 & case 3 \\
\hline \hline $28.5 \mathrm{MPa} / 600^{\circ} \mathrm{C} / 620^{\circ} \mathrm{C}$ & 450 & $\mathbf{5 0 0}$ & 550 \\
\hline $27.5 \mathrm{MPa} / 560^{\circ} \mathrm{C} / 580^{\circ} \mathrm{C}$ & 400 & 450 & $\mathbf{5 0 0}$ \\
\hline $35.0 \mathrm{MPa} / 700^{\circ} \mathrm{C} / 720^{\circ} \mathrm{C}$ & $\mathbf{5 0 0}$ & 550 & 600 \\
\hline
\end{tabular}

- There are three distinct values of the cooling flow temperature set in the calculations. These values correspond to the size of the turbine higher live steam temperature is matched with higher cooling temperature. All the values applied in the calculations are written in Tab. 2. 
The value of $500{ }^{\circ} \mathrm{C}$ is used with all three of the analyzed cycles. The results obtained from simulations for this value allow to compare the influence of the cooling system on various scale turbines.

\section{Modeling of the cooling system}

The flow of the cooling steam is subject to a complex heat transfer process. However in the assessment of the cycle performance the most important aspect is the influence of the coolant on the main flow. This problem has been discussed for example in [6] and [7]. The results of the analysis given in those references proved that the major impact on the expansion line results form the mixing between the cooling and the main flow.

The heat transfer process, although crucial for the protection of the components of the turbine, has significantly smaller effect on the temperature of the flow in the steam path. This is due to the high amount of steam in the main flow - even the most intensive heat transfer between the main flow, the cooled components and the coolant does not influence much the main flow temperature. It may be neglected when evaluating the performance of the whole cycle.
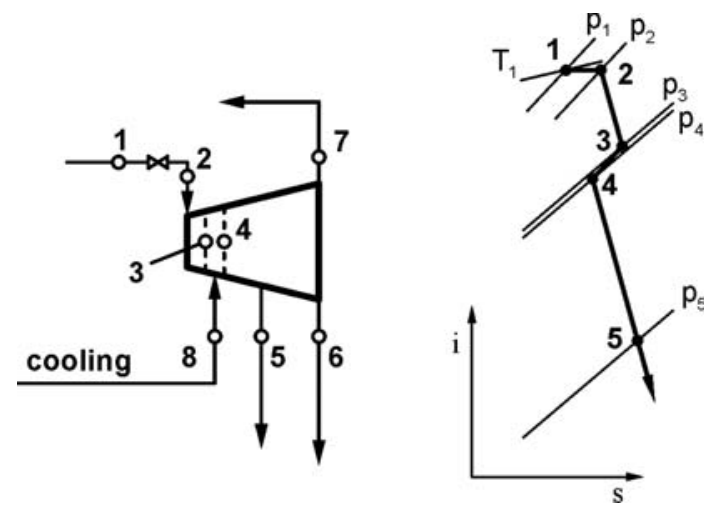

Figure 5. Mixing process.

Therefore the simulations used in the analysis described in this paper involved a simplified approach towards modeling of the cooling. This approach is explained in Fig. 5. The cooling flow is injected into the main flow after the first stage of the turbine. The enthalpy drop in the first stage depends on the type of the turbine (reaction or impulse) and it is set as 
an input value for the calculations. The mixing process lowers the temperature of the main flow and changes its expansion line. This is shown in Fig. 5 in the enthalpy-entropy coordinate system: cooling and mixing process correspond to the line between points 3 and 4 .

\section{Modeling of the thermal states}

The effects of the cooling on the thermal state of turbine components is analyzed here for the high pressure rotor. It is exposed to steam at various temperature, including the cooling steam. These flows create boundary conditions for the analysis of the temperature distribution.

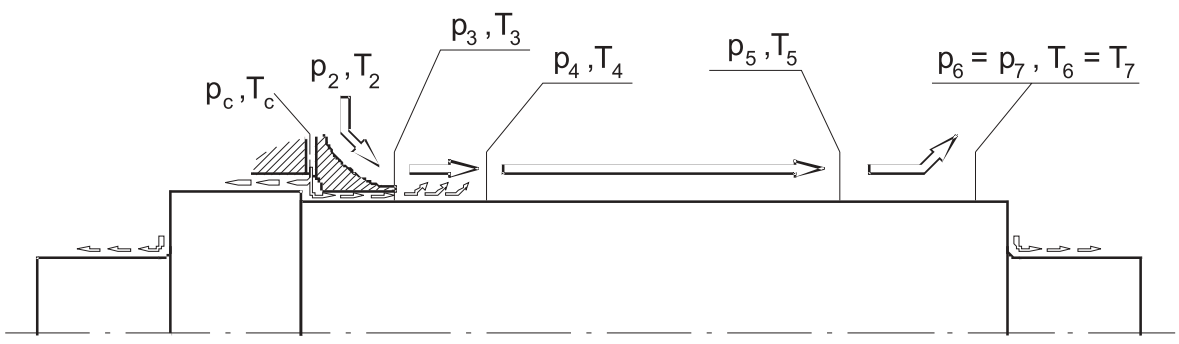

Figure 6. High pressure rotor and steam flows near its surface.

The symbols of the steam parameters refer to Fig. 6, where the mixing process is described. Live steam enters the turbine at pressure $p_{2}$ and temperature $T_{2}$. However the rotor is exposed to the cooling flow in the steam inlet area at initial parameters $p_{c}$ and $T_{c}$. The cooling steam temperature increases as it gains the heat from the rotor. Detailed description of this problem is given in [8] and [9]. At the segment that follows the inlet area the mixing process occurs between the main and the cooling flow. In the result main flow reaches pressure $p_{4}$ and temperature $T_{4}$ (see also Fig. 5). Then it expands to the parameters at the extraction and further to the parameters at the turbine outlet.

\section{High pressure turbine cooling}

The change of the cooling conditions in the high pressure turbine part was first analyzed for a supercritical steam turbine with live and reheat steam parameters of $28.5 \mathrm{MPa} / 600{ }^{\circ} \mathrm{C} / 620{ }^{\circ} \mathrm{C}$ (see also Tab. 1 case A). 
The results of the simulations are shown in Fig. 7. There are two values under the investigation: the power output (Fig. 7a) and power generation efficiency (Fig. 7b).

a)

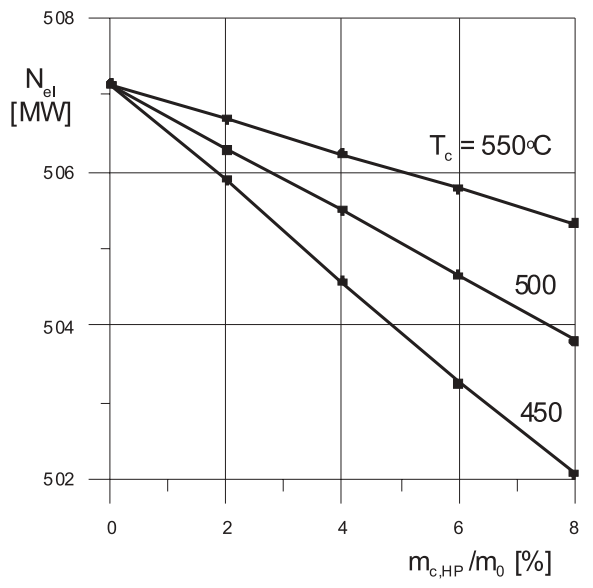

b)

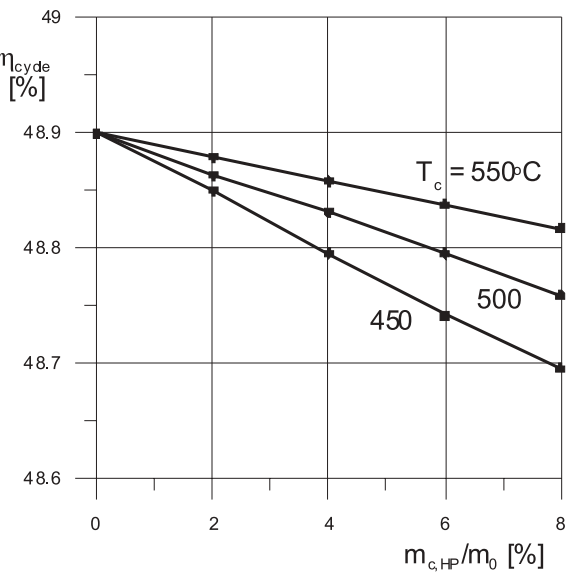

Figure 7. Power output and power generation efficiency for various cooling conditions in the HP turbine part and live steam temperature $600{ }^{\circ} \mathrm{C}$.

As expected the most intensive cooling at $450{ }^{\circ} \mathrm{C}$ and the $\mathrm{m}_{c, H P} / \mathrm{m}_{0}$ ratio at $8 \%$ causes the highest power and efficiency decrease. For the supercritical turbine under the investigation the maximal power drop was $5 \mathrm{MW}$, which is about $1 \%$ of the power output of the cycle without the cooling system. Smaller amounts of the cooling steam as well as higher cooling temperature result in lower decrease of power and efficiency. However the cooling process is less intensive and may not be sufficient to maintain appropriate conditions of operation for the material of the turbine components.

The main reason for the efficiency decrease is the temperature drop due to the mixing process. For the most intensive cooling the difference between the temperature of the main flow before and after the mixing slightly exceeds $11 \mathrm{~K}$. The expansion lines modified due to the mixing are plotted in Fig. 8 in the enthalpy-entropy coordinate system. The lines in Fig. 8 correspond to cycles with 4 and $8 \%$ of the cooling flow. The line for an uncooled expansion is also shown for the comparison. The presence of the cooling shifts the expansion lines towards lower values of entropy (to the left side of the enthalpy-entropy diagram). 


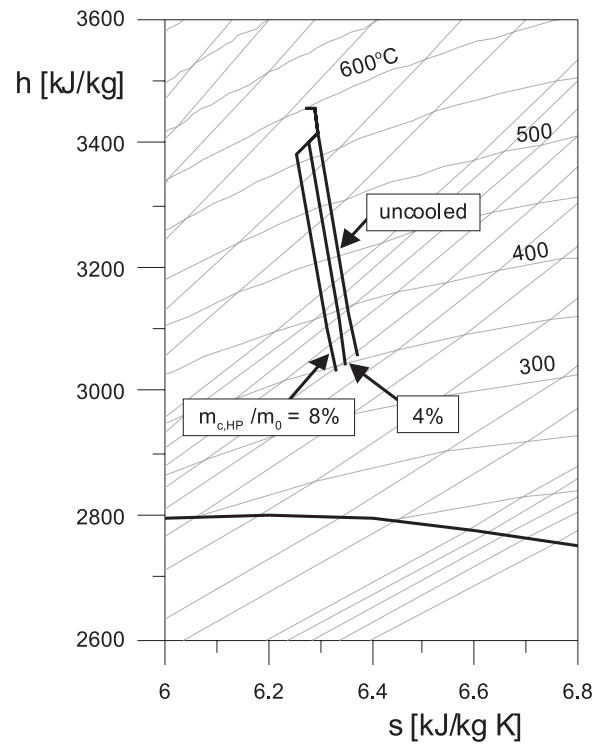

Figure 8. High pressure expansion with and without cooling.

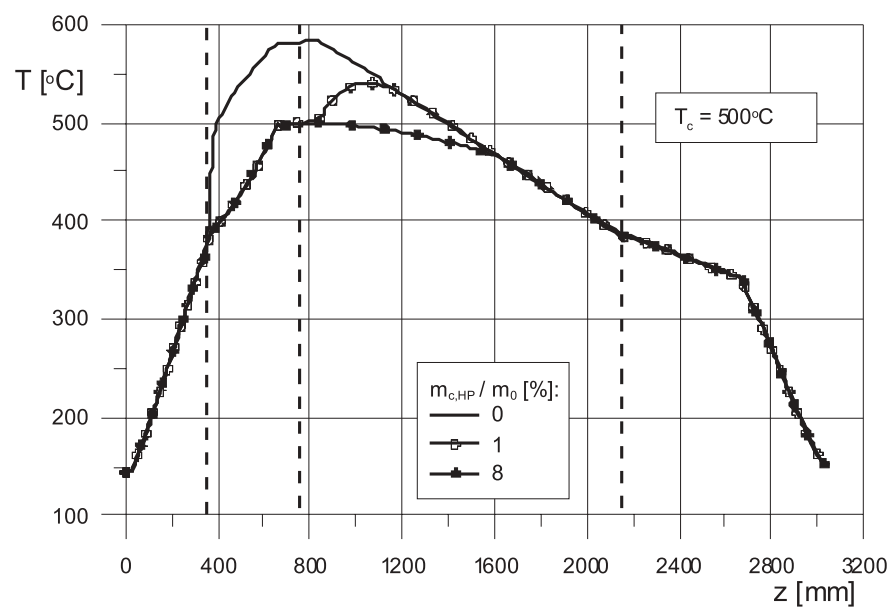

Figure 9. Temperature at the surface of the HP rotor for various cooling conditions.

Thermal effects of the cooling process are visible in Fig. 9. Plots presented in this figure show the temperature distribution at the surface of the HP rotor for two different amounts of the cooling steam and for an uncooled rotor. In the latter case maximal temperature value at the rotor surface is 
$583{ }^{\circ} \mathrm{C}$. A cooling system with $1 \%$ of the cooling ratio decreases this value to $540{ }^{\circ} \mathrm{C}$, although a local maximum is clearly visible. A better, more uniform temperature distribution at the surface is achieved for $8 \%$ cooling ratio, while maximal temperature drops down to $500{ }^{\circ} \mathrm{C}$.

The shapes of the lines representing the temperature distribution at the surface of the rotor result from the temperature of the steam near the rotor. Figure 10 presents temperature of the steam in the main flow and at the surface of the HP rotor. These graphs were obtained for two amounts of the cooling steam (cooling ratio at 1\% in Fig. 10a and $8 \%$ in Fig. 10b).

a)

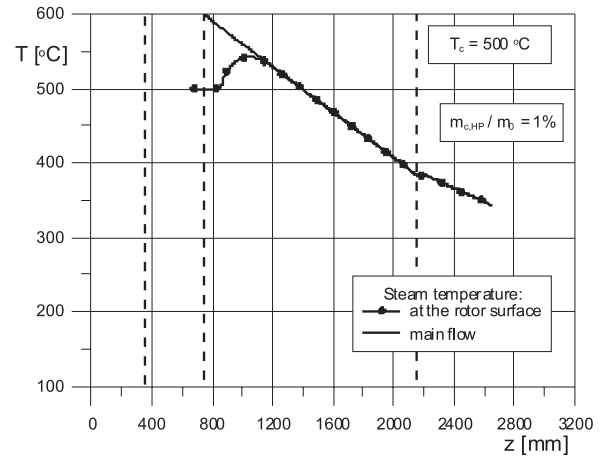

b)

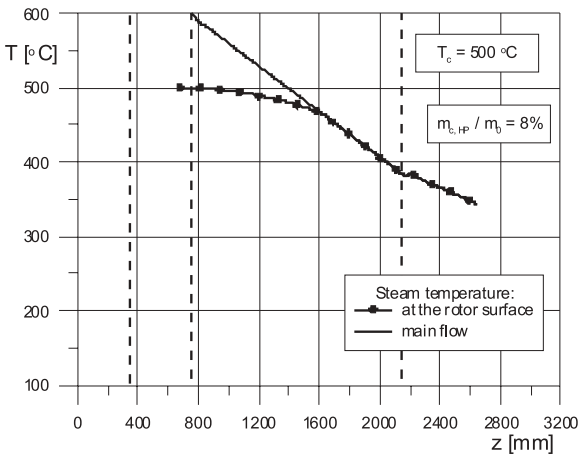

Figure 10. Steam temperature in the main flow and at the surface of the HP rotor.

It may be seen in the figure that the point where the temperature of the steam at the surface becomes equal to the temperature of the main flow is located in various distance from the live steam inlet. This means that bigger amounts of the cooling flow result in bigger area of the rotor surface that is exposed to the cooling steam at lower temperature.

Further calculations involved cases B and C from Tab. 1. The dependency between the power generation efficiencies and cooling conditions are similar to the trend observed for case A. All the results are compared in Fig. 11. The graphs in the figure show the efficiency in the relation to the amount of the HP cooling flow for three different cycles but with the same temperature of the coolant $\left(500{ }^{\circ} \mathrm{C}\right)$. This results show clearly that despite of the negative influence of the cooling flow on the cycle performance, the efficiency is always better for the cycle with higher live steam temperature. For example point A1 in Fig. 11 (case A1 with live steam at $600{ }^{\circ} \mathrm{C}$ - see Tab. 1, and cooling flow at $500{ }^{\circ} \mathrm{C}$ - see Tab. 2) corresponds to a cycle with $8 \%$ of the $m_{c, H P} / m_{0}$ ratio that provides higher efficiency than case 


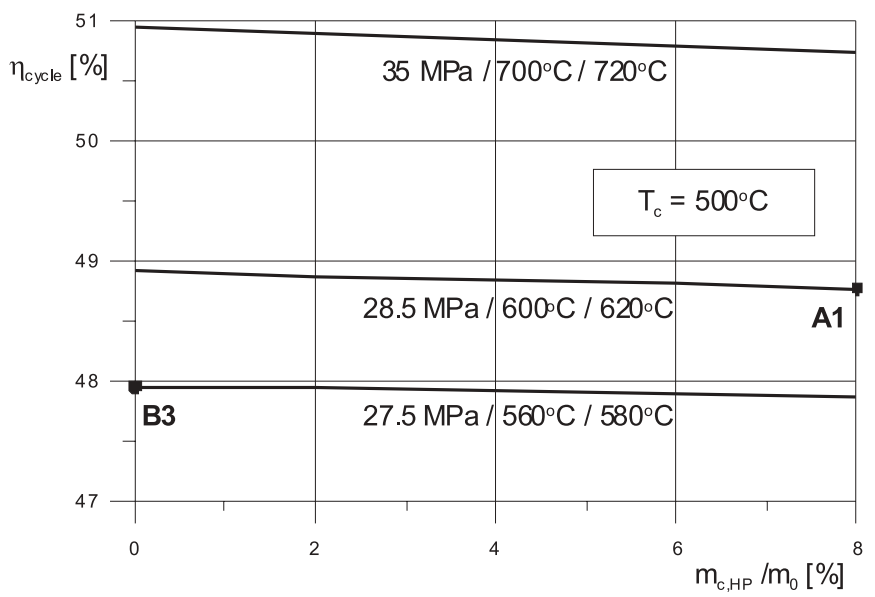

Figure 11. Cycle efficiencies for various live steam temperatures and $T_{c}=500{ }^{\circ} \mathrm{C}$.

B3 (live steam at $\left.560{ }^{\circ} \mathrm{C}\right)$ without any cooling $\left(m_{c, H P} / m_{0}\right.$ ratio equal to zero). This proves the advantage of a cycle with a cooling system: even very intensive cooling guarantees better performance than uncooled cycle at lower live steam parameters.

\section{$7 \quad$ Intermediate pressure turbine cooling}

The results of the simulations for various cooling conditions in the intermediate part of the turbine are shown in Fig. 12. The graphs were obtained for the $28.5 \mathrm{MPa} / 600{ }^{\circ} \mathrm{C} / 620^{\circ} \mathrm{C}$ steam turbine. The results follow the trends observed earlier for the HP cooling.

It may be noticed that in this case the maximal power drop for the most intensive cooling is lower than the drop for the high pressure cooling. The same is true for the power generation efficiency. This means that the change of the cooling conditions in the IP turbine part has lower influence on the performance of the whole cycle.

The combined effects of both HP and IP cooling systems are shown in Fig. 13. Calculations in this case were run for the same percentage of the cooling flow in both turbine parts with cooling systems. The total effect is cumulated and the power output as well as the efficiency both decrease much faster with more intensive cooling. 
a)

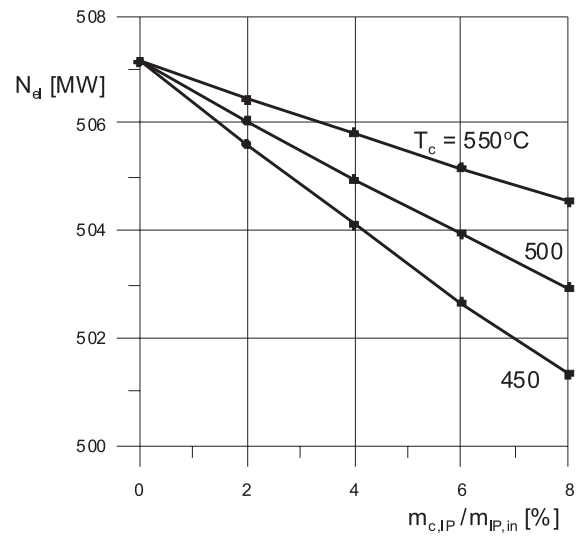

b)

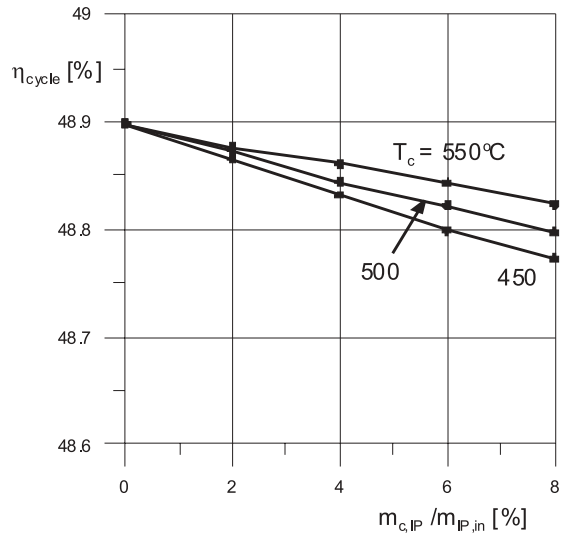

Figure 12. Power output and power generation efficiency for various cooling conditions in the IP turbine part (reheat steam at $620^{\circ} \mathrm{C}$ ).

a)

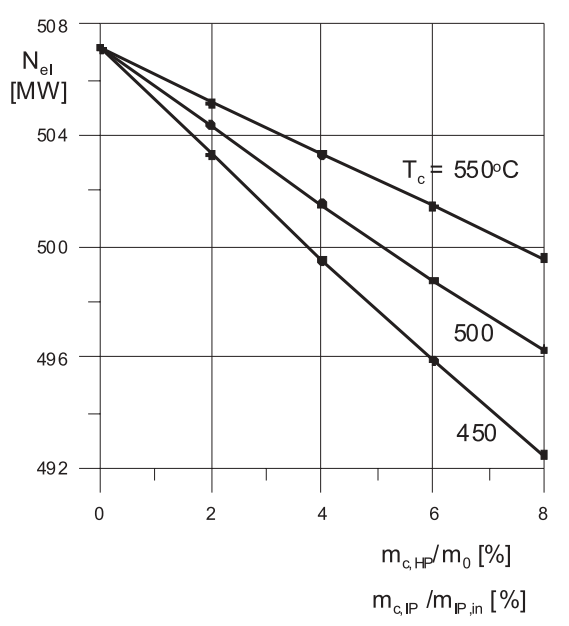

b)

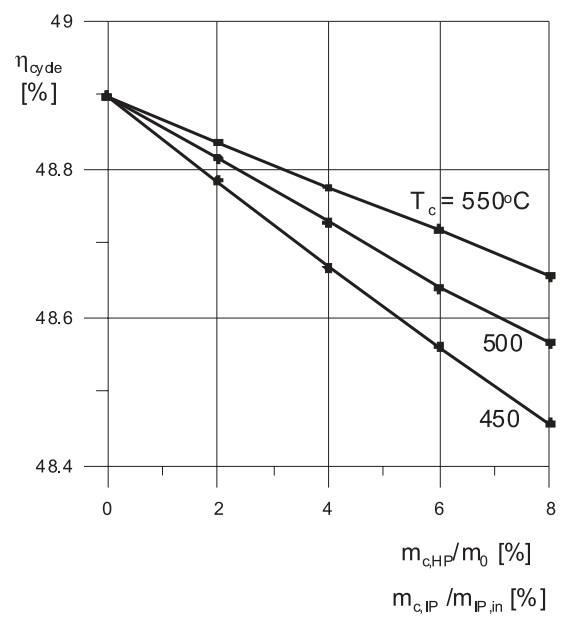

Figure 13. Combined effect of the HP and IP cooling system.

\section{Conclusions}

Cooling systems become an essential part of designs of supercritical steam turbines because they allow to decrease thermal loads in the main components. This primary effect is achieved even with small amounts of a cooling 
flow (see Fig. 9 and the discussion of the results presented there). However better effects require more intensive cooling and that affects the performance of the steam cycle.

This second aspect was analyzed in the research presented in this paper. The results prove that more intensive cooling worsens the power generation efficiency but the efficiency drop is much less than the gain from the increased live and reheat steam parameters. The problem of the efficiency drop may then be reversed: for a given maximal allowable temperature of the material the presence of the cooling allows to apply higher live and re-

heat steam temperatures and obtain better overall efficiency of the electric power generation.

Received 15 June 2010

\section{References}

[1] Quinkertz R., Ulma A., Gobrecht E., Wechsung M.: USC Turbine technology for maximum efficiency and operational flexibility. Siemens Technical Papers, AG 2008.

[2] Cziesla F., Bewerunge J., Senzel A.: Luenen - State-of-the-Art Ultra Supercritical Steam Power Plant Under Construction. PowerGen Europe 2009.

[3] Susta M.R.: Latest development in Supercritical Steam Technology. PowerGen Asia 2008.

[4] Beer J.M.: Higher Efficiency Power Generation Reduces Emissions. US National Coal Council, Issue Paper 2009.

[5] Zachary J., Kochis P., Narula R.: Steam Turbine Design Considerations for Supercritical Cycles. CoalGen, Milwaukee 2007.

[6] Chmielniak T., Kosman W., Kosman G.: Simulation modules of thermal processes for performance control of combined heat and power plant with a gas turbine unit. Applied Thermal Engineering 27(2007), Issue 12.

[7] Chmielniak T., Kosman W.: Expansion line modeling and strength diagnostics of internally cooled gas turbines. ASME paper GT2004-53550, ASME TURBO EXPO 2004.

[8] Kosman W.: The possibilities to reduce thermal loads in the casing of the supercritical steam turbines. Archives of Thermodynamics 30(2009), No. 4.

[9] Kosman W.: Thermal analysis of cooled supercritical steam turbine components. Energy 35(2010), Issue 2. 